\title{
Psychiatric Disorder and Violent Behaviour
}

\author{
Lefter Sinani $^{1}$, Fabian Cenko ${ }^{2}$ \\ ${ }^{1}$ Psychiatric Hospital, University Hospital Centre "Mother Teresa”, Tirana, Albania. \\ ${ }^{2}$ Faculty of Medicine in Tirana, Tirana, Albania
}

\begin{abstract}
Violent behaviour of patients is a common problem in emergency psychiatric evaluation, diagnosis, management and treatment of which is very difficult. The aim was to identify risk and protective factors of violent behaviours and to establish the degree to which the HCR-20 predicts the frequency and severity of violent behaviour. the highest rate of violence in a decreasing scale is reported in subjects with antisocial and borderline personality disorders (91\%); Bipolar disorders (70\%); substance abuse disorders (66\%) and psychotic patients (57\%). The fig.1 demonstrate the high correlation amongst positive value of HCR-20 test with risk for violence behaviour (O.R=7.91, 95\%CI 4.3-14.4). The variables that mostly accompany the value of HCR-20 test are: H1 (previous violence behavior) in $86 \%$ of the sample, $\mathrm{H5}$ (substance abuse problems) in $81 \%$, H6 (major mental illneses) in $69 \%$, $\mathrm{H} 9$ (personality disorders) in $61 \%$ and C3 (active symptoms of major mental illnesses) in 79\% of the sample. Individual HCR20 score represents a good indicator suggesting appropriate measures to be taken in order to prevent unwanted consequences in EW enviorenment.
\end{abstract}

Keywords: violent behaviour, psychiatric disorder, delusional thinking

\section{Introduction}

Violent behavior of patients is a common problem in emergency psychiatric evaluation, diagnosis, management and treatment of which is very difficult. Psychosis is not a diagnosis, but it is a symptom that can be found in a number of disorders, including schizophrenia, delusional disorder, neurological and medical disorders, substance abuse disorders, and mood disorders, especially with mania. When psychosis is present, regardless of the disorder, it increases the risk of violence $(1,2)$. The psychotic paranoid patient, regardless of diagnosis, poses a problem because his or her delusions may not be obvious or the patient may attempt to hide them. Therefore, the evaluator must listen for subtle clues and should follow up regarding the assessment of violence toward others but must be careful not to confront the patient with insistent questioning about the presence of paranoid delusions $(3,4)$. A manic patient may become violent as a result of delusional thinking in which the patient believes he or she is being persecuted because of some special attribute. Manic patients usually put all their impulses, including violent ones, into action. A typical situation in which manic patients erupt with violence is when they feel contained and not free to do what they want to do $(5,6)$. The absence of a test that could be used to predict violent behavior hampers proper decision in the case of emergency admissions, as well as discharge from the hospital. The application of such a test would upgrade assessment offering solve this problem. Improve assessment, management and treatment of patients with violent behaviors in the psychiatric ward. A history of noncompliance with treatment should alert the clinician that the patient is at an increased risk of violent behaviour (7). Noncompliance may be indicated by a history of irregular attendance at scheduled appointments or laboratory and other clinical workups, or by the patient's refusing to take certain medications for a psychiatric or medical disorder or deliberately missing doses of medication $(8,9)$. Demographic characteristics of patients should be considered in the assessment of violence potential. Young persons and men have been found to be at increased risk of violence, as are persons from environments of poverty, familial disruption, or decreased social control in which violence is considered an acceptable means of attaining a goal in the absence of other legitimate means or adequate education. The environment from which the patient comes is thus an important consideration in the determination of violence potential $(10,11)$. The aim was to identify risk and protective factors of violent behaviours and to establish the degree to which the HCR-20 predicts the frequency and severity of violent behaviour.

\section{Material and Method}

Twenty-four weeks prospective cohort study. Psychiatric evaluation to patients admited in emergency ward (EW) of psychiatric hospital at UHC "Mother Tereza" was done based on structural clinical interviews and questionnaires related to violent behaviors and risk factors. Participants were assessed with the HCR-20 test upon admission to the EW. The frequency and severity of violent incidents during the follow-up in EW were measured by application of MOAS test. Further quality information regarding violent incidents was collected through staff interviews. To determine interrater reliability in this study $10 \%$ of the participants were assessed by more than one clinician. Statistical analyses of the study database were done with SPSS package version 16 .

\section{Results and Discussion}

According to our data, the relationship between violence and mental illness vary considerably across different diagnoses. Thus, according to table 1 the highest rate of violence in a decreasing scale is reported in subjects with antisocial and borderline personality disorders (91\%); Bipolar disorders (70\%); substance abuse disorders (66\%) and psychotic patients $(57 \%)$. The fig. 1 demonstrate the high correlation amongst positive value of HCR-20 test with risk for violence behaviour (O.R=7.91, 95\%CI 4.3-14.4). The variables that mostly accompany the value of HCR-20 test are: H1 (previous violence behavior) in $86 \%$ of the sample, H5 (substance abuse problems) in $81 \%$, H6 (major mental 


\section{International Journal of Science and Research (IJSR) \\ ISSN (Online): 2319-7064 \\ Index Copernicus Value (2013): 6.14 | Impact Factor (2015): 6.391}

illneses) in 69\%, H9 (personality disorders) in 61\% and C3 (active symptoms of major mental illnesses) in $79 \%$ of the sample. HCR20 test shows good results to predict both future violence or not in patients frequenting $\mathrm{EW}$ in a university psychiatric hospital ( $\mathrm{PPV}=79 \%$ and $\mathrm{PNV}=67 \%$ ). The overall accuracy of this test is good $(74 \%)$. Violence by persons with antisocial personality disorder is often vicious and persistent. They will continue punching, or hitting with objects, beyond what is needed to subdue the other person and win the fight. These patients have no remorse for their actions, and the victim is perceived as deserving the beating. The person with borderline personality disorder can be violent and make suicidal gestures when rejected or feeling rejected by others. The violence and suicide attempts are part of a broader picture of impulsivity and instability of interpersonal relationships $(12,13)$. Persons with narcissistic personality can be violent occasionally when angry, such as when they are not given something they think they deserve. The person with paranoid personality rarely attacks those seen as persecutors, but when violence does occur it can be severe, even taking the form of mass murder $(14,15)$. The person with intermittent explosive disorder is violent during circumscribed episodes, often with little apparent precipitating cause or out of proportion to any identifiable cause (16).

\section{Conclusions}

Violence is endemic and epidemic. Its roots and causes are many and complex. Violence is not a diagnosis, although it can be associated with psychiatric conditions. People arrested for violent acts come under the jurisdiction of law enforcement agencies and the judicial system. Many have mental disorders. Few are seen by psychiatrists. Some offenders are diverted to mental health courts and forensic treatment facilities. Although psychiatrists and other mental health professionals consult with these agencies, their encounters with individuals who behave violently or have violent thoughts usually occur in the treatment of outpatients and inpatients. For clinicians in the trenches, evaluating and treating patients with violent ideations and behaviors can be anxiety-provoking, frustrating, sometimes dangerous, and occasionally legally fraught.

Individual HCR20 score represents a good indicator suggesting appropriate measures to be taken in order to prevent unwanted consequences in EW enviorenment. It is important for the personnel in EW to be in alert if at least one of the following factors are present in the admitted patient(s): preivous violence, psychotic patients or substance abuse.

\section{References}

[1] Volavka J, Laska E, Baker S, et al. History of violent behaviour and schizophrenia in different cultures. Analyses based on the WHO study on Determinants of Outcome of Severe Mental Disorders. Br J Psychiatry. 1997 Jul. 171:9-14.
[2] Fazel S, Grann M. The population impact of severe mental illness on violent crime. Am J Psychiatry. 2006. 163:1397-1403.

[3] Swinson N, Flynn SM, While D, et al. Trends in rates of mental illness in homicide perpetrators. $\mathrm{Br} \mathrm{J}$ Psychiatry. 2011 Jun. 198:485-9.

[4] Citrome L. Compelling or irrelevant? Using number needed to treat can help decide. Acta Psychiatr Scand. 2008 Jun. 117(6):412-9.

[5] Volavka J, Citrome L. Heterogeneity of violence in schizophrenia and implications for long-term treatment.Int J Clin Pract. 2008 Aug. 62(8):1237-45.

[6] Nolan KA, Citrome L. Reducing inpatient aggression: does paying attention pay off?. Psychiatr Q. 2008 Jun. 79(2):91-5.

[7] Nolan KA, Citrome L, Volavka J. Violence in schizophrenia:The roles of psychosis and psychopathy. J Pract Psychiatry Behav Health. 1999. 5:326-35.

[8] Nolan KA, Czobor P, Roy BB, et al. Characteristics of assaultive behavior among psychiatric inpatients.Psychiatr Serv. 2003. 54:1012-1016.

[9] Nolan KA, Volavka J, Czobor P, et al. Aggression and psychopathology in treatment-resistant inpatients with schizophrenia and schizoaffective disorder. J Psychiatr Res. 2005. 39:109-115.

[10] Blacklock N. Domestic violence: working with perpetrators, the community and its institutions. Advances in Psychiatric Treatment. 2001. 7:65-72.

[11] Fang X, Massetti GM, Ouyang L, Grosse SD, Mercy JA. Attention-deficit/hyperactivity disorder, conduct disorder, and young adult intimate partner violence. Arch Gen Psychiatry. 2010 Nov. 67(11):1179-86.

[12] Citrome L. The psychopharmacology of violence with emphasis on schizophrenia, part 2: long-term treatment. J Clin Psychiatry. 2007 Feb. 68(2):331-2.

[13] Citrome L, Green L. The dangerous agitated patient. What to do right now. Postgrad Med. 1990 Feb 1. 87(2):231-6.

[14] Citrome L, Volavka J. Schizophrenia: Violence and comorbidity. Curr Opin Psychiatry. 1999. 12:47-51.

[15] Nolan KA, Czobor P, Roy BB, et al. Characteristics of assaultive behavior among psychiatric inpatients.Psychiatr Serv. 2003. 54:1012-1016.

[16] Nolan KA, Volavka J, Czobor P, et al. Aggression and psychopathology in treatment-resistant inpatients with schizophrenia and schizoaffective disorder. J Psychiatr Res. 2005. 39:109-115.

Table 1: Diagnoses of mental illnesses

\begin{tabular}{|c|c|c|c|}
\hline No. & Diagnoses & $\begin{array}{c}\text { Total } \\
\text { cases }\end{array}$ & $\begin{array}{c}\text { Violent cases } \\
(\mathrm{n} \%)\end{array}$ \\
\hline 1 & $\begin{array}{c}\text { Antisocial and borderline } \\
\text { personality disorders }\end{array}$ & 22 & $20(91 \%)$ \\
\hline 2 & Bipolar disorders & 54 & $38(70 \%)$ \\
\hline 3 & Substance abuse disorders & 44 & $29(66 \%)$ \\
\hline 4 & Psychotic patients & 129 & $74(57 \%)$ \\
\hline
\end{tabular}


International Journal of Science and Research (IJSR)

ISSN (Online): 2319-7064

Index Copernicus Value (2013): 6.14 | Impact Factor (2015): 6.391

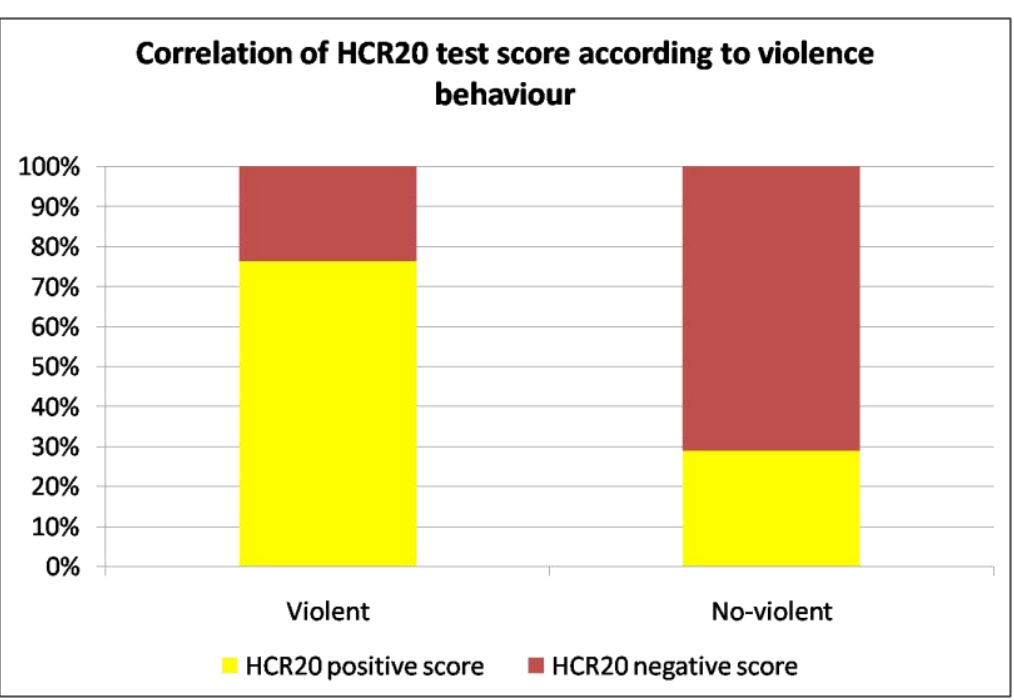

Figure 1: Correlation of HCR-20 test with risk for violence behaviour

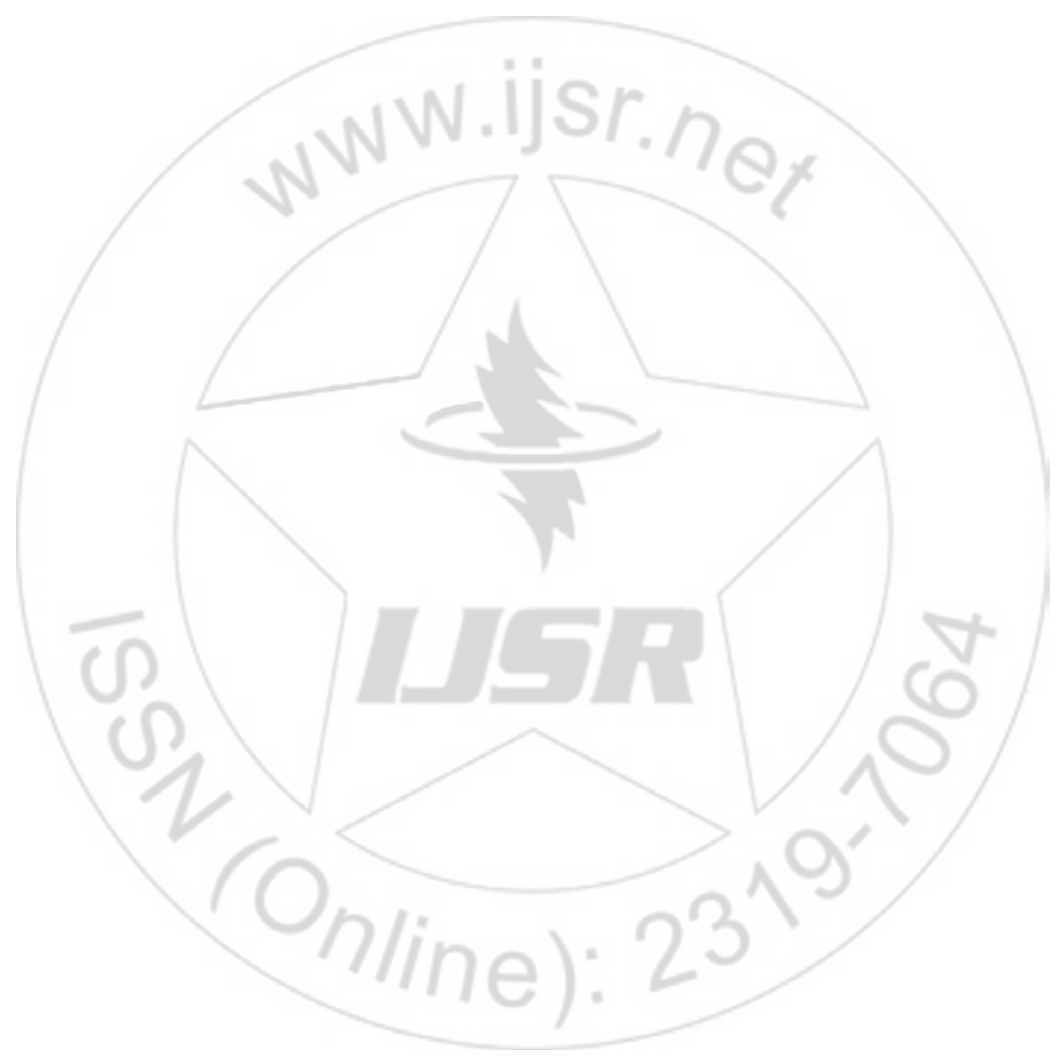

Volume 5 Issue 5, May 2016 